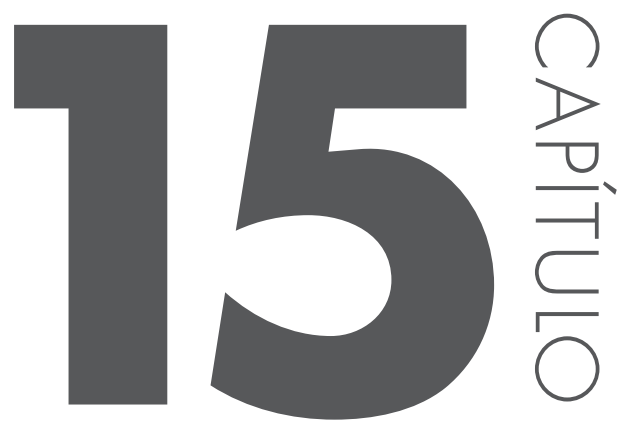

\title{
AGRICULTORES FAMILIARES E REPRODUÇÃO SOCIAL: as comunidades Cruzeiros dos Martírios e Paulistas no município de Catalão (GO)
}

Silva, Juniele Martins ${ }^{1 *}$; Mendes, Estevane de Paula Pontes ${ }^{2}$

1 Doutoranda em Geografia, Universidade Estadual Paulista, Campus Presidente Prudente. Integrante do Núcleo de Estudos e Pesquisas Socioambientais (NEPSA/UFG/CNPq)

2 Professora Doutora do Programa de Pós-graduação em Geografia, Universidade Federal de Goiás, Regional Catalão. Coordenadora do Núcleo de Estudos e Pesquisas Socioambientais (NEPSA/UFG/CNPq)

*email: junielemartins@yahoo.com.br

\section{RESUMO}

Os estudos sobre agricultura familiar no Brasil tiveram maior enfoque a partir da década de 1990. A emergência da expressão deve-se a duas esferas: a) no campo político condicionado aos embates dos movimentos sociais e a criação do Programa Nacional de Fortalecimento da Agricultura Familiar (PRONAF); e b) por intermédio de alguns trabalhos acadêmicos. Essas unidades de produção são entendidas como um segmento em que a propriedade e o trabalho estão ligados à família, e, esses possuem aspectos culturais próprios atravessados de geração a geração, formando suas identidades territoriais. Nesse sentido, examinaram-se as principais características da produção familiar, com ênfase na perspectiva de 
sucessão hereditária e do patrimônio sociocultural das comunidades Cruzeiro dos Martírios e Paulistas, Catalão (GO). Para a realização desta pesquisa foi efetuada uma revisão da literatura pertinente à temática, pesquisa documental e pesquisa de campo. Esses produtores lançam mão de estratégias produtivas e culturais que contribuem para a sua produção/reprodução. Todavia, verificase nessas comunidades o processo em curso de envelhecimento da população, 'masculinização' e migração dos jovens. Essas tendências podem comprometer a sucessão hereditária dessas unidades de produção.

Palavras-chave: Agricultura familiar; Sucessão hereditária; Comunidades Cruzeiro dos Martírios e Paulistas, Catalão (GO)

Silva, Juniele Martins; Mendes, Estevane de Paula Pontes; "AGRICULTORES FAMILIARES E REPRODUÇÃO SOCIAL: as comunidades Cruzeiros dos Martírios e Paulistas no município de Catalão (G0)", p. 241-255 . In: Seminário de Pesquisa, Pós-Graduação e Inovação da Regional Catalão (2. : 2014 : Goiás) Coletânea Interdisciplinar em Pesquisa, Pós- Graduação e Inovação - Volume 1 : Estudos Ambientais, Território e Movimentos Sociais. Anais [livro eletrônico] / organizado por Adriana Freitas Neves, Idelvone Mendes Ferreira, Maria Helena de Paula, Petrus Henrique Ribeiro dos Anjos. São Paulo: Blucher, 2015. ISBN: 978-85-8039-109-1, 


\section{INTRODUC̣ÃO}

A agricultura familiar é entendida como o segmento em que a família, ao mesmo tempo em que é proprietária dos meios de produção, assume o trabalho no estabelecimento produtivo. Os agricultores familiares possuem, ainda, uma identidade territorial formada em bases materiais/objetivas e imateriais/ subjetivas e constituída a partir das relações estabelecidas com o território e com a cultura. Essa relação envolve valores, tradições, crenças e costumes.

A agricultura familiar no Brasil apresenta diversidades e diferenciações regionais, o que torna importantes os estudos e as análises de localidades específicas para a compreensão da organização e reprodução desse segmento. Nesse sentido, analisaram-se as principais discussões sobre a agricultura familiar, dando ênfase nas perspectivas da sucessão hereditária e do patrimônio sociocultural das comunidades Cruzeiro dos Martírios e Paulistas, no município de Catalão, Estado de Goiás.

Esta discussão é resultado da pesquisa intitulada "Agricultura familiar e territorialidade: as comunidades Cruzeiro dos Martírios e Paulistas, Catalão (GO)", desenvolvida junto ao Programa de Pós-graduação em Geografia (nível Mestrado), da Universidade Federal de Goiás, Campus Catalão, concluída em 2011. Soma-se a isso a experiência adquirida no desenvolvimento de pesquisas vinculadas ao Núcleo de Estudos e Pesquisas Socioambientais (NEPSA, CNPq), Regional Catalão/Universidade Federal de Goiás, o que justifica a realização desse estudo.

A escolha das comunidades Cruzeiro dos Martírios e Paulistas se deu, principalmente, pelas características internas das unidades produtivas, como o uso da mão de obra predominantemente familiar, o tamanho das propriedades (área média em torno de 46,33ha), os rendimentos (a maioria entre 1 e 3 salários mínimos), a multiplicidade de mecanismos e a diversidade de competências, o que resulta em estratégias de reprodução dessas famílias. Salienta-se que a comunidade Cruzeiro dos Martírios fez parte da minha infância, como sujeito atuante e participante da realidade local (habitei de 1985 a 2002 na comunidade, cerca de 17 anos). Constituí minha identidade na Comunidade e, ainda, possuo um sentimento de pertencimento com o lugar, além dos laços de amizade e de parentesco lá estabelecidos. Quanto à escolha da comunidade Paulistas, esta deve-se aos aspectos econômicos e socioculturais semelhantes aos da comunidade Cruzeiro dos Martírios, como também pela proximidade $(50 \mathrm{~km})$ entre elas, o fatores que ampliam o universo da pesquisa e permite enriquecer a análise. 
O estudo pautou-se na pesquisa teórica sobre: a) agricultura familiar; b) sucessão hereditária; c) migrações; d) envelhecimento; e e) masculinização. A pesquisa de campo foi feita em 2010 e 2011 nas comunidades Cruzeiro dos Martírios (74 sedes/residências) e Paulistas (34 sedes/residências). As entrevistas foram realizadas junto aos chefes de famílias e/ou seus cônjuges, sendo aplicados um total de 15 roteiros de entrevista na Cruzeiro dos Martírios e 11 na Paulistas, o que representa respectivamente uma amostra de $20,27 \%$ e $32,35 \%$.

As comunidades rurais estão localizadas na parte Nordeste do município. Martírios está aproximadamente $90 \mathrm{~km}$ da sede municipal e $20 \mathrm{~km}$ do Distrito de Santo Antônio do Rio Verde. Seu acesso dá-se pela BR-050, no sentido Catalão (GO) - Brasília (DF). A Paulistas fica aproximadamente a $150 \mathrm{~km} \mathrm{da}$ sede municipal; seu acesso dá-se pela BR-050 e situa-se à margem direita do rio São Marcos (Figura 1).

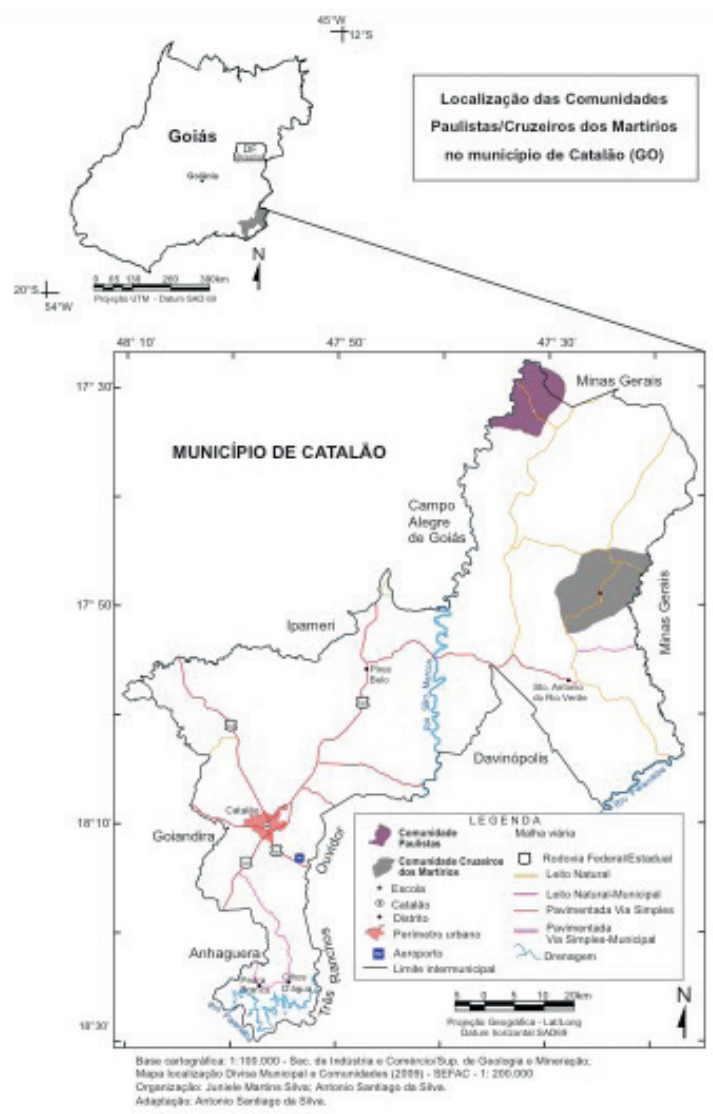

Figura 1 - Localização das comunidades Cruzeiro dos Martírios e Paulistas, município de Catalão (G0) - 2010.

Fonte: Secretaria de Indústria e Comércio e Superintendência de Geologia e Mineracãõo. 
Nas comunidades rurais estudadas, as famílias encontram-se fortemente ligadas através dos laços de consanguinidade, de parentesco e de amizade, associados com a terra e com os vínculos territoriais, com sentimentos partilhados e crenças comuns. As relações mais profundas e intensas podem ser expressas pelo afeto e solidariedade. Assim, os agricultores familiares veem na comunidade e na relação com a terra, não apenas um modo de produzir, mas também um modo de viver. Isso estabelece uma identidade cultural, e de pertencimento, que conduz a uma valorização da particularidade e das diferenciações regionais e étnicas.

Para facilitar a discussão proposta, o texto encontra-se dividido nas seguintes subseções: "Agricultura familiar: a interdependência entre terra, trabalho e família", "A sucessão hereditária: envelhecimento da população, composição das famílias, migração dos jovens e 'masculinização"”.

\section{AGRICULTURA FAMILIAR: A INTERDEPENDÊNCIA ENTRE TERRA, TRABALHO E FAMÍLIA}

A agricultura familiar caracteriza-se pela relação entre terra, trabalho e família e apresenta uma série de especificidades e diferenciação regional/local, que asseguram sua inserção e reprodução na sociedade contemporânea. Trata-se de um segmento que possui uma relação de pertencimento com o território através de seus costumes, valores, práticas, saberes e crenças.

No Brasil, as pesquisas sobre a produção familiar na agricultura foram retomadas a partir da década de 1990. São vários os estudos no campo da Sociologia, da Economia, da Antropologia e da Geografia, os quais têm ressaltado a importância econômica, cultural e política da agricultura familiar.

Os enfoques destas pesquisas, geralmente, são: a) importância da agricultura familiar na produção de gêneros alimentícios básicos, que garantem o consumo familiar e a reprodução da própria família; b) formas de produção/reprodução na sociedade contemporânea; c) dificuldades de reprodução do patrimônio sociocultural; e d) práticas culturais, com ênfase nos laços de parentesco, vizinhança, solidariedade, tradições, valores e costumes.

A agricultura familiar apresenta uma capacidade de adaptação às novas circunstâncias da sociedade. Sua inserção ao mercado dá-se em meio às várias dificuldades enfrentadas para manterem-se na atividade agrícola. E suas estratégias de reprodução resultam da multiplicidade de mecanismos e da diversidade de competências.

Os agricultores familiares enfrentam as dificuldades por meio das condições 
e instrumentos que possuem e aprenderam a usar ao longo de suas vidas. A respeito disso, Wanderley (2001, p. 35, grifos da autora) pondera que “[...] os agricultores familiares modernos enfrentam os novos desafios com as armas que possuem e que aprenderam a usar a partir de sua experiência.”

No que se refere à sua integração e adaptação na agricultura moderna, Tedesco (2001) avalia que estas unidades agrícolas passaram a adotar diferentes tipos de estratégias para enfrentar os desafios. Para o autor,

[...] o agricultor familiar adota estratégias e aciona formas de racionalidades possíveis, enfrenta os desafios com as condições objetivas e os instrumentos que lhe são possíveis e ao seu alcance, dentre os quais a dimensão da historicidade que lhe é inerente e a incipiente participação nas políticas públicas. (TEDESCO, 2001, p. 13).

Uma das principais estratégias adotadas pelos pequenos agricultores é a diversificação das atividades, de tal forma, esta se constitui em uma de suas características mais importantes. Esta diversificação destina-se não só a ampliar o leque de produtos comercializáveis, como também visa assegurar o consumo familiar.

A reprodução da agricultura familiar no Brasil é um processo dinâmico sujeito às transformações e adaptações no âmbito da sociedade, considerada em toda sua diversidade e complexidade. O modo como os agricultores utilizam e/ou operacionalizam os recursos produtivos e suas relações com os mercados, deve ser considerado não apenas em concordância com as variáveis estruturais (terra, capital e trabalho), mas também com uma série de fatores sociais, econômicos, demográficos e culturais.

$\mathrm{O}$ entendimento das características da agricultura familiar perpassa pela relação propriedade, trabalho e família. Deve-se considerar que essa combinação assume no tempo e no espaço uma grande diversidade de formas sociais. Assim, esse arranjo permite dar ao segmento certo sentido de particularidade e, do mesmo modo, a construção de tipologias, mesmo na diversidade e na diferenciação. 


\section{A SUCESSÃO HEREDITÁRIA: COMPOSIC̣ÃO DAS FAMÍLIAS, MIGRAÇÃO DOS JOVENS, 'MASCULINIZAC̣ÃO' E ENVELHECIMENTO DA POPULAC̣ÃO}

A temática envolvendo a reprodução social da agricultura familiar tem se destacado nas pesquisas voltadas para o rural brasileiro. Isso pode ser atribuído aos elevados índices migratórios do meio rural em direção às cidades, com predomínio de jovens e de mulheres. Como respostas a essa tendência têm-se o envelhecimento e a masculinização da população rural, e, consequentemente, os problemas referentes à sucessão dos estabelecimentos rurais.

A agricultura familiar vem enfrentando vários problemas, como demanda irregular do mercado, alto preço de insumos, baixos preços de seus produtos, desvalorização de sua cultura, baixo nível de escolaridade, baixa renda, envelhecimento da população, migração dos jovens, moradias precárias, precariedade nos acessos/estradas, falta de lazer, dificuldades no acesso à assistência médica hospitalar, entre outros. Quanto ao sistema de financiamentos e assistência técnica, estes são quase inexistentes nas comunidades. Supõe-se que esses impasses têm contribuído para a migração de jovens e de famílias para as cidades.

Diante disso, verifica-se nas comunidades Cruzeiro dos Martírios e Paulistas que a idade dos produtores rurais está acima de cinquenta anos. Nessas comunidades, a média de idade dos homens é de 56,83 anos e das mulheres 54,64 anos (Tabela 1). Em ambas as comunidades foi verificado o envelhecimento da população, responsável por favorecer o elevado índice de aposentadorias $(36,05 \%)$. Esse envelhecimento da população do meio rural é consequência das relações com o modo de vida urbano. Nota-se que desde os conteúdos dos livros didáticos, o vestuário até a alimentação contribuem para a valorização da cultura urbana.

Tabela 1 - Média de idade dos homens e mulheres: comunidades Cruzeiro dos Martírios e Paulistas, Catalão (GO) - 2011.

\begin{tabular}{ccc}
\hline COMUNIDADE & IDADE DO HOMEM & IDADE DA MULHER \\
\hline CRUZEIRO DOS MARTÍRIOS & 56,14 & 52,53 \\
\hline PAULISTAS & 57,09 & 56,75 \\
\hline MÉDIA & 56,83 & 54,64
\end{tabular}

Fonte: Pesquisa de campo $(2010,2011)$. Org.: Silva (2011). 
Outro fator importante sobre o meio urbano é a atração que ele exerce, principalmente, nos jovens que migram para as cidades em busca de emprego e de estudos. Nessa perspectiva, Camarano e Abramovay (1999), ao analisarem o êxodo rural, o envelhecimento e a 'masculinização' da população rural no Brasil, entre as décadas de 1950 e 1990, advertem que no fluxo migratório rural está ocorrendo um "rejuvenescimento", ou seja, a maior saída de jovens.

Em ambas as comunidades o tamanho médio das famílias (pessoas) é baixo. Na comunidade Cruzeiro dos Martírios é de 2,86 e na Paulistas é de 2,36. Assim, pode-se inferir que a disponibilidade de mão de obra destinada às atividades mais emergenciais no rural é escassa. Para Caume (2005), a insuficiência de mão de obra constitui um fator limitante à execução do processo produtivo e às possibilidades de sucesso da exploração. Essa realidade pode ser atribuída à redução da taxa de fecundidade e à migração para outras áreas, geralmente para as cidades. Pode-se observar, nesse contínuo, que tem sido uma tendência a permanência de apenas o chefe e a esposa nas propriedades.

Supõe-se que a diminuição dos jovens no meio rural e, consequentemente nas comunidades estudadas, pode ser associada à queda da taxa de fecundidade. Sobre o assunto, Moreira (1998), ao discutir o envelhecimento da população brasileira, diz que uma das mais significativas mudanças demográficas, observadas no Brasil nos últimos decênios do século XXI, foi à redução dos níveis de fecundidade nacional, verificada em todas as classes sociais e regiões do país.

Nas comunidades em estudo, o número médio de filhos por família é de 2,94. A maioria $(2,74)$ dos filhos possui idade superior a 12 anos. Os filhos com idade inferior a 12 anos representam apenas 0,2 (Tabela 2). Observa-se, ainda, que na comunidade Paulistas não há nenhum filho com idade inferior a 12 anos. Esses dados indicam o número reduzido de crianças no meio rural.

Tabela 2 - Média de filhos por família: comunidades Cruzeiro dos Martírios e Paulistas, Catalão (G0) - 2011.

\begin{tabular}{cccc}
\hline COMUNIDADE & NÚMERO DE FILHOS & FILHOS $<12$ ANOS & FILHOS $>12$ ANOS \\
\hline CRUZEIRO DOS MARTÍRIOS & 3,53 & 0,4 & 3,13 \\
\hline PAULISTAS & 2,36 & - & 2,36 \\
\hline MÉDIA & 2,94 & 0,2 & 2,74 \\
\hline
\end{tabular}

Fonte: Pesquisa de campo (2010 e 2011). Org.: Silva (2011).

$\mathrm{Na}$ comunidade Cruzeiro dos Martírios, os filhos que possuem menos de 12 anos residem com os pais. Em relação aos filhos acima de 12 anos, 
aproximadamente 0,27 moram com os pais nos estabelecimentos, 1,33 residem no meio rural e 1,53 vivem no meio urbano. Na Paulistas, apenas, 0,09 dos filhos acima de 12 anos residem com os pais, enquanto 2,27 migraram para o meio urbano (Tabela 3). Esses dados apontam que a migração para as cidades tem sido elevada em ambas as comunidades, representando uma média 1,9. Os jovens procuram as cidades, principalmente, em busca de emprego e estudo. De modo geral, a cidade mais procurada é Catalão (GO).

As dificuldades encontradas pelos jovens, quanto ao acesso à terra, justifica o desestímulo para a continuidade destes no campo. Abramovay (2001), ao discutir os impasses sociais da sucessão hereditária no oeste de Santa Catarina, aponta que o grande desafio está em estabelecer políticas de acesso à terra que permitam transmitir estas propriedades para aqueles jovens que desejam continuar na profissão de agricultor.

Tabela 3 - Local que residem os filhos > 12 anos: comunidades Cruzeiro dos Martírios e Paulistas, Catalão (GO) - 2011.

\begin{tabular}{ccccc}
\hline COMUNIDADE & FILHOS $>$ 12 ANOS & COM OS PAIS & MEIO RURAL & MEIO URBANO \\
\hline CRUZEIRO DOS MARTíRIOS & 3,13 & 0,27 & 1,33 & 1,53 \\
\hline PAULISTAS & 2,36 & 0,09 & - & 2,27 \\
\hline MÉDIA & 2,74 & 0,18 & 0,66 & 1,9 \\
\hline
\end{tabular}

Fonte: Pesquisa de campo (2010 e 2011). Org.: Silva (2011).

Os jovens desejam uma independência financeira através do trabalho remunerado, o que, na maioria das situações, não acontece quando eles trabalham na propriedade com seus pais, além de não conseguirem trabalho regular fora de seus estabelecimentos. É comum os pais disponibilizarem parte da propriedade para os filhos, mas qualquer concessão de terra do pai para o filho pode comprometer a estabilidade da família, devido o tamanho da propriedade. Acrescenta-se a dificuldade de obtenção de terra, de conhecimento técnico e acesso de políticas públicas para o segmento.

A insuficiência dos serviços de saúde, educação e lazer são outros fatores decisivos para a migração dos jovens para a cidade. Eles veem na cidade a oportunidade de continuarem e/ou concluírem seus estudos e, consequentemente, inserirem-se no mercado de trabalho com atividades menos desgastantes e remuneradas.

A partir dos dados obtidos com a pesquisa, pressupõe-se que a sucessão do patrimônio nessas comunidades está comprometida, porque os filhos, frente 
às dificuldades, não mostram interesse e/ou não tem condições em permanecer nas propriedades. Assim, a terra e o patrimônio sociocultural transmitido de geração a geração encontra-se ameaçado. Abramovay et al. (2001) denomina esse fenômeno de "crise de reprodução social". De modo geral, isso implica na incorporação gradativa das unidades familiares de produção pelas grandes propriedades.

Muitos estabelecimentos, nas comunidades estudas, poderão não ter sucessor e, assim, inviabilizar sua continuidade. Para Spanevello e Lago (2008), a agricultura familiar é marcada por determinadas características e especificidades que diferem estes agricultores de outras categorias sociais. Desse modo, principalmente quanto à continuidade da profissão paterna, o surgimento de uma nova geração de agricultores acontece no interior dos próprios estabelecimentos, através da socialização no trabalho e no modo de vida. Nesse sentido, a continuidade dos estabelecimentos familiares depende da permanência dos filhos e da vontade de herdar o patrimônio familiar.

As discussões que tratam da sucessão hereditária dos estabelecimentos rurais, além de sublinharem o envelhecimento da população, a migração, e a falta de políticas públicas, realçam a 'masculinização' da população rural. Para Abramovay (2001, p. 16), “[...] ao envelhecimento acopla-se, mais recentemente, um severo processo de masculinização da juventude [...]”

Nas comunidades rurais, a migração seletiva (maior saída das moças do que dos rapazes) favorece a 'masculinização' no meio rural, uma vez que o número de homens que permanecem é maior em relação ao de mulheres. Esse processo, consequentemente, dificulta a constituição de novas famílias. A Tabela 4 mostra o número superior de pessoas do sexo masculino nas comunidades, em que a média é de $55,58 \%$, enquanto o número de mulheres representa uma média de $44,40 \%$.

Tabela 4 - População do sexo masculino e feminino em \%: comunidades Cruzeiro dos Martírios e Paulistas, Catalão (GO) - 2011.

\begin{tabular}{ccc}
\hline COMUNIDADE & NÚMERO DE HOMENS & NUMERO DE MULHERES \\
\hline CRUZEIRO DOS MARTÍRIOS & 53,48 & 46,51 \\
\hline PAULISTAS & 57,69 & 42,30 \\
\hline MÉDIA & 55,58 & 44,40 \\
\hline
\end{tabular}

Fonte: Pesquisa de campo (2010 e 2011). Org.: Silva (2011). 
Camarano e Abramovay (1999) ponderam algumas hipóteses para explicar o maior índice migratório de mulheres em relação aos homens: a) as migrações estão relacionadas diretamente à oferta de trabalho no meio urbano e o predomínio de moças vincula-se à expansão do setor de serviços, tanto em empresas como em residências; b) o caráter seletivo das migrações está ligado às dinâmicas intrafamiliares, em que as moças têm uma carga de trabalho intensa, no interior das unidades de produção familiares, sem qualquer contrapartida ou valorização de seu trabalho que lhes indiquem horizontes atrativos para sua permanência no campo; e c) a melhor formação educacional que as moças recebem, já com vistas a projetos futuros fora da agricultura, estes motivados pela própria família.

O envelhecimento da população é decorrente da migração dos jovens para as cidades em busca de emprego e estudo, como também em função da queda da taxa de fecundidade. Deve-se enfatizar, ainda, a 'masculinização' dos jovens como resultado da maior migração de jovens do sexo feminino. Nesse sentido, supõe-se o comprometimento da sucessão hereditária nas unidades familiares de produção, como mostram Camarano e Abramovay (1999) e Abramovay (2001).

\section{CONSIDERAC̣ÕES FINAIS}

$\mathrm{Na}$ agricultura familiar prevalece uma interdependência entre os fatores terra, trabalho e família. Destacam-se aspectos peculiares quanto aos seus costumes, tradições e hábitos, formados especialmente pela religiosidade. E, ainda, as relações de parentesco, reciprocidade e solidariedade que são estabelecidas nas comunidades e territórios. Tais aspectos constituem o patrimônio sociocultural, transmitido de geração a geração. A produção é outra característica relevante desse grupo, sendo destinada, principalmente, para o consumo familiar e o excedente é comercializado.

No que tange o tamanho das propriedades, verifica-se que na maioria (73,32\%) dos agricultores da comunidade Cruzeiros dos Martírios a área média das explorações pesquisadas é em torno de 46,33ha, enquanto na comunidade Paulistas essa média é superior (154,45ha). Constatou-se que a diferença entre o tamanho das propriedades não garantem melhores rendimentos entre os produtores das comunidades Paulistas e Cruzeiro dos Martírios. Essa situação pode ser creditada às condições naturais dos solos e à falta de políticas públicas (federal, estadual e municipal) direcionadas ao setor. A renda mensal das famílias nas comunidades, é em média entre 1 e 2 salários mínimos, o que representa 
40\% na comunidade Martírios e 54,54\% na Paulistas.

A inserção dessas famílias rurais na economia de mercado tem promovido o envelhecimento da população, a 'masculinização' e a migração dos jovens para as áreas urbanas. A média de idade dos produtores nas comunidades Cruzeiro dos Martírios e Paulistas é considerada elevada (56,83 anos). O caráter seletivo das migrações refere-se à maior saída das moças em relação aos rapazes, favorecendo a 'masculinização' no meio rural. Por isso, o número de homens que permanecem no campo é maior em relação ao de mulheres, o que dificulta a constituição de novas famílias. E, como resultado desse processo, tem-se o comprometimento da sucessão hereditária.

A migração dos jovens para o meio urbano dá-se pela oportunidade de independência financeira, posto que não conseguem obtê-la na unidade familiar. Acrescenta-se a isso a busca pelo estudo/qualificação e lazer. Logo, a urbanização e a industrialização devem ser consideradas nesse contexto.

A partir desses pressupostos, acredita-se que o futuro dessas comunidades rurais esteja comprometido. A maioria dos filhos dos produtores não tem condições em assumir a sucessão, o que prejudica a sucessão do patrimônio sociocultural. Essa realidade favorece a incorporação gradativa das pequenas propriedades pelas grandes. Nesse sentido, enfatiza-se a necessidade do envolvimento do Estado, de políticas públicas e órgãos voltados para as necessidades desse segmento de produtores na ruralidade brasileira. 


\section{Title: Family Farmers And Social Reproduction: The Communities Cruzeiro Dos Martírios And Paulistas In Municipality Of Catalão (Go)}

\section{Abstract}

The studies about familiar agriculture in Brazil had more focus from the decade of 1990. The emergence of expression is due to two spheres: the political field, conditioned to the conflicts of social movements and establishment of the National Program of Invigoration of the Familiar Agriculture (PRONAF); and b) by means of some academic studies. These production units are understood as a segment in which the property and work are linked to the family, and these have particular and cultural aspects crossed from generation to generation, forming their territorial identities. In that sense, the main characteristics of family production have been examined, with emphasis on the perspective of hereditary succession and socio-cultural patrimony of Cruzeiro dos Martírios and Paulistas Communities in Catalão (GO). To conduct this study, a review of pertinent literature about the thematic, documental research and field research were made. These producers use productive and cultural strategies that contribute to their production/reproduction. However, the ongoing process of aging of the population, 'masculinization' and migration of the young people appears in these communities. These tendencies can compromise the hereditary succession of these production units.

Keywords: Familiar agriculture. Hereditary succession. Cruzeiro dos Martírios and Paulistas Communities, Catalão (GO). 


\section{REFERÊNCIAS}

ABRAMOVAY, R. (Coord.). Juventude e agricultura familiar: desafios dos novos padrões sucessórios. Brasilia: UNESCO, 1998. 104 p.

ABRAMOVAY, R. (Coord.). Os impasses sociais da sucessão hereditária na agricultura. Florianópolis: Epagri, 2001. 120 p.

ABRAMOVAY, R. Paradigmas do capitalismo agrário em questão. São Paulo: Hucitec, 1992. 275 p. (Estudos Rurais, 12).

BLUM, R. Agricultura familiar: um estudo preliminar da definição, classificação e problemática. In: TEDESCO, J. C. (Org.). Agricultura familiar: realidades e perspectivas. 3. ed. Passo Fundo: UPF, p. 57-104, 2001.

BRUMER, A.; ANJOS, G. dos. Gênero e reprodução social na agricultura familiar. Revista Nera, Presidente Prudente, ano 11, n. 12, p. 6-17, jan./jun. 2008. Disponível em: <http://www2.fct. unesp.br/nera/revistas/12/6_brumer_e_anjos_12.pdf>. Acesso em: 14 set. 2012.

CAMARANO, A. A.; ABRAMOVAY, R. Êxodo rural, envelhecimento e masculinização no Brasil: panorama dos últimos 50 anos. Rio de Janeiro: IPEA, 1999. 1-28 p. Disponível em: <http://www. dominiopublico.gov.br/download/texto/td_0621.pdf>. Acesso em: 21 jun. 2011.

CAUME, D. J. A agricultura familiar no estado de Goiás. Goiânia: UFG, 1997.71 p. (Quiron). FAO/INCRA, Diretrizes de política agrária e desenvolvimento sustentável: 0 resumo do relátorio final do projeto UTF/BRA/036. 2. versão, 1996.

LAMARCHE, H. (Coord.). Agricultura familiar: comparação internacional. Tradução de Ângela M. N. Tiiiwa. Campinas: Unicamp, v. 1-2, 1993. (Colecão Repertórios).

MENDES, E. de P. P. A produção rural familiar em Goiás: as comunidades rurais no município de Catalão. 2005. 294 f. Tese (Doutorado em Geografia - Desenvolvimento Regional e Planejamento Ambiental) - Faculdade de Ciências e Tecnologia, Universidade Estadual Paulista, Presidente Prudente, 2005.

MOREIRA, M. de M. 0 envelhecimento da população brasileira: intensidade, feminização e dependência. Revista Brasileira de Estudos Populacionais, Brasilia, v. 15, n. 1, p. 79-93, 1998 Disponivel em: <http:www.abep.nepo.unicamp.brdocs/rev_inf/vol15_n.1_1998/vol15_ nl_1998_5artigo_79_94.pdf >. Acesso em: 21 jun. 2011.

SCHNEIDER, S. A pluriatividade na agricultura familiar. Porto Alegre: UFRGS, 2003. 254 p.

SCHNEIDER, S. Agricultura familiar e teoria social: a diversidade das formas familiares de a diversidade das formas familiares de produção na agricultura, 2008. Disponível em: <http://simposio. cpac.embrapa.br/palestras/painel10/palestrapainel10sergio.pdf>. Acesso em: 27 abr. 2010.

SILVA, J. M. Agricultura familiar e territorialidade: as comunidades Cruzeiro dos Martírios e Paulistas no município de Catalão (GO). 2011. 170 f. Dissertação (Mestrado em Geografia) Universidade Federal de Goiás, Campus Catalão, Catalão, 2011.

SPANEVELLO, R, M.; LAGO, A. Arranjos e encaminhamentos da heranca na agricultura familiar. CONGRESSO DA SOCIEDADE BRASILEIRA DE ECONOMIA, ADMINISTRAÇÃO E SOCIOLOGIA RURAL, 46, 
2008, Rio Branco. Anais eletrônicos... Rio Branco: Sociedade Brasileira de Economia, Administração e Sociologia Rural, 2008. Disponivel em: <http://www.sober.org.br/palestra/9/329.pdf>. Acesso em: 8 jun. 2011.

TEDESCO, J. C. (Org.). Agricultura familiar: realidades e perspectivas. 3. ed. Passo Fundo: UPF, 2001. $405 \mathrm{p}$.

TEDESCO, J. C. Terra, trabalho e familia: racionalidade produtiva e ethos camponês. Passo Fundo: EDIUPF, 1999. $331 \mathrm{p}$.

VENÂNCIO, M. Território de esperança: tramas territoriais da agricultura familiar na comunidade rural São Domingos em Catalão (G0). 2008. 178 f. Dissertação (Mestrado em Geografia) - Instituto de Geografia, Universidade Federal de Uberlândia, Uberlândia, 2008.

WANDERLEY, M. N. B. Raizes históricas do campensinato brasileiro. In: TEDESCO, J. C. (Org.). Agricultura familiar: realidades e perspectivas. 3. ed. Passo Fundo: UPF, p. 21-55, 2001. WOORTMANN, K. Com parente não se neguceia: 0 campesinato como ordem moral. Anuário Antropológico. Brasilia: UNB, 1990, p. 11-73. Disponível em: <http://www.tempobrasileiro.com. br/antropo.htm>. Acesso em: 25 abr. 210. 
Seminário de Pesquisa, Pós-Graduacãoo e Inovação da Regional Catalão 